\title{
Condition and morphometric changes in tilapia (Oreochromis sp.) after an eradication attempt in Southern Louisiana
}

\author{
O. Thomas Lorenz', Patrick Smith², Lyndon Coghill ${ }^{3}$ \\ I Department of Biological Sciences, Georgia Southwestern State University, 800 GSW State University Drive, \\ Americus, GA 317092 Pontchartrain Institute of Environmental Sciences, University of New Orleans, 2045 \\ Lakeshore Drive, New Orleans, Louisiana 701223 Field Museum of Natural History, 1400 S Lake Shore \\ Drive, Chicago, IL, USA 60605 \\ Corresponding author: O. Thomas Lorenz (otto.lorenz@gsw.edu)
}

Academic editor: E. García-Berthou| Received 6 March 2013 | Accepted 5 November 2013 | Published 24 January 2014

Citation: Lorenz OT, Smith P, Coghill L (2014) Condition and morphometric changes in tilapia (Oreochromis sp.) after an eradication attempt in Southern Louisiana. NeoBiota 20: 49-59. doi: 10.3897/neobiota.20.5062

\begin{abstract}
A hybrid form of tilapia was introduced into Port Sulphur, Louisiana and was subsequently managed by treatment with rotenone and stocking of native predatory fishes. Measurements of tilapia from before this management event were compared to measurements of tilapia in the two years after the treatment. Post-management tilapia were consistently deeper in body and had greater weight per unit length (condition) when compared to pre-management fish. Procrustes generalized least squares data supported this by consistently finding post-management tilapia to be consistently deeper in body and head shape than pre-management fish. Although this could indicate the effectiveness of stocking native predators, several other factors, including two cold winters, seasonal effects, and less competition, may have contributed to this result.
\end{abstract}

\section{Keywords}

Ivasive, tilapia, morphology, eradication, cichlid 


\section{Introduction}

Previous work has shown that both natural and human impacts can change the morphology of populations. Grant and Grant (2002) and Witte et al. (2008) found that changes can occur as a fixed result over years, while Tollrian and Harvell's (1999) work found it could occur within a generation as phenotypic plasticity. Rapid morphological change has been observed as a response to predation in a variety of species, including plants, cladocerans (Stibor 1992), snails (Brönmark et al. 2011) and fishes (Brönmark and Miner 1992). Fish have shown repeatedly that they can alter their body change in response to predators. Brönmark and Miner (1992) suggested that Crucian Carp (Carassius carassius) could increase their body depth to prevent their consumption by Northern Pike (Esox lucius). Additional studies have shown that Western Mosquitofish, Gambusia affinis, can also change their morphology in response to predators. In contrast to the Crucian Carp, G. affinis have been shown to decrease their body depth, improving their biomechanical capacity for escape (Langerhans et al. 2004). In addition to predation, other factors can affect fish morphology as well, such as salinity (Collyer et al. 2005), water velocity (Imre et al. 2002) and stunting (Chizinski et al. 2010). A previous study examining tilapia found that invasive Oreochromis mossambicus exhibit a decrease in body depth when compared to their native populations (Firmat et al. 2012).

Tilapia, in particular the genus Oreochromis, have been introduced extensively and are listed as one of the 100 worse invasive species in the world (Lowe et al. 2000). Eradication and understanding of their invasive biology is an important concern to protect biodiversity and local fisheries. Although tilapia are a common invasive, no study has examined morphological changes in invasive tilapia after eradication efforts. In Port Sulphur, Louisiana there was an introduction of an unknown tilapia species into a seven-mile canal system. Over one million invasive tilapia were killed by rotenone treatment in the summer of 2009 in an eradication attempt monitored by Louisiana Department of Wildlife and Fisheries. No Largemouth Bass (Micropterus salmoides), gar (Lepisosteidae), or other species capable of eating an adult tilapia were collected after the rotenone treatment. One month after rotenone treatments, a variety of predatory fish were then stocked by LDWF and a monitoring program was put in place for the next several years. Ten tilapia were collected during the next two years and then they were not observed for two more years, from April 2011 until at least February of 2013 (Lorenz, unpublished data). The tilapia collected after rotenone treatment and predator stocking were noticeably unique in appearance, apparently with a deeper body.

Of note, Firmat et al. (2012) observed a strong effect of phylogenetic history on morphology, regardless of a variety of environmental conditions faced by multiple populations of invasive $O$. mossambicus. This would indicate the importance of founder effect as opposed to phenotypic plasticity. The unique aspect of this Louisiana population is the possibility of multiple founder events (the initial founding population and the founders that survived rotenone and/or other environmental effects). 


\section{Methods}

Twenty pre-management tilapia were collected by the initial rotenone treatment (2009), and ten post-management tilapia were collected by electrofishing (2010). Electrofishing was performed in the identical location to where fish were sampled before rotenone, within 100 meters of where the canal passes under Highway 23, north of Port Sulphur, Louisiana $\left(29^{\circ} 31^{\prime} 29.87^{\prime \prime N}, 89^{\circ} 44^{\prime} 49.89^{\prime W}\right)$. Standard length (SL) of each fish was measured to the nearest $0.1 \mathrm{~cm}$ on a Wildco fish measuring board, and body mass $(\mathrm{BM})$ was weighed to the nearest $0.1 \mathrm{~g}$ on a Ohaus Navigator portable scale. Body depth was also measured to the nearest $0.1 \mathrm{~cm}$ and all specimens were photographed by a digital camera (Pentax K-10D).

\section{Analysis of Covariance Models}

Two different analysis of covariance (ANCOVA) tests were performed to compare fish pre and post management. Each measurement (standard length, body depth, and weight) was $\log _{10}$-transformed prior to analysis for allometric scaling. The predictor variables for both ANCOVAs were standard length and a factor designating whether each individual fish was pre or post management (hereafter referred to as year). The first ANCOVA weight as a response variable and the second used body depth as a response variable. The design of these tests was to see if year was a significant predictor for either response variable with standard length as a covariate $(a=0.05)$. Each model initially included an interaction between year and standard length. If the interaction term was not statistically significant (at $a=0.05$ ), it was removed. The ANCOVAs were created using R statistical software package version 2.12.1 (R Core Team 2012).

\section{Geometric Morphometrics}

Standardized photographs of individuals were entered into TPSDig2 where 15 landmarks were placed on each individual to generate the $x$ and $y$ coordinates used for further analyses (Rohlf 2005). Landmarks were chosen in a fashion similar to Klingenberg et al. (2003), with additional measurements to indicate other possible morphological changes, such as eye size (Figure 1). Landmark files were imported into MorphoJ version $1.04 \mathrm{a}$ where partially generalized Procrustes coordinates were generated (Rohlf and Slice 1990, Rohlf and Marcus 1993, Klingenberg 2011).

The Procrustes coordinates were then used to generate principal components (PCs). A multivariate analysis of covariance (MANCOVA) design was then implemented with two covariates, and year as predictor variables. The response variable of this model was all PC components with an eigenvalue $>1$ (PC1 - PC5), accounting for $82 \%$ of the variance. Previously, centroid size alone has been used as a covariate for similar MANCOVAs, but in this case it was also found to be correlated with standard 


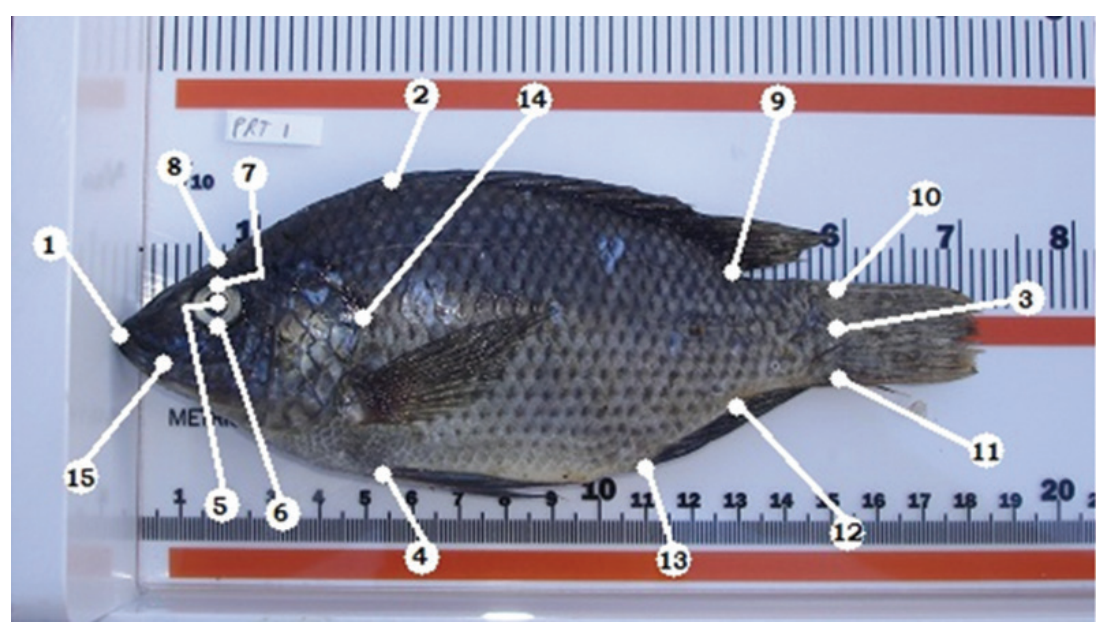

Figure I. Description of the landmarks. I tip of snout at fold anterior to ethmoid/nasal bones, with mouth closed $\mathbf{2}$ anterior base of dorsal fin $\mathbf{3}$ base of the caudal fin at the level of the lateral line $\mathbf{4}$ anterior base of the anal fin $\mathbf{5}$ center of the eye $\mathbf{6}$ bottom of the eye $\mathbf{7}$ top of the eye $\mathbf{8}$ edge of the head directly above the center of the eye $\mathbf{9}$ posterior end of the dorsal fin base $\mathbf{I} \mathbf{0}$ base of the caudal fin, dorsal II base of the caudal fin, ventral $\mathbf{I} \mathbf{2}$ posterior end of the anal fin base $\mathbf{I} \mathbf{3}$ anterior end of the anal fin base $\mathbf{I} \mathbf{4}$ most posterior edge of operculum $\mathbf{I} \mathbf{5}$ corner of the mouth, where maxillary angle rests when the mouth is closed

length (Firmat et al. 2012). For our study, it was not highly correlated with standard length $\left(\mathrm{R}^{2}=0.028, \mathrm{p}=0.432\right)$, therefore both standard length and centroid size were used as covariates in our MANCOVA. All interactions were initially included in the model and any non-significant $(a=0.05)$ terms were removed step-wise with higher order interactions being removed first.

A between groups PCA (bgPCA) was also performed. We modified the bgPCA section of the ordination program for $\mathrm{R}$ statistical software found in Zeldich et al. (2012) for this part. To remove the effects of centroid size and standard length, residuals from a multivariate regression were used (Shape $\sim$ centroid size + standard length). The deformation along the first $\mathrm{PC}$ axis was plotted for each coordinate as this has been suggested as a preferred method for interpreting the change in shape data between groups (Mitteroecker and Bookstein 2011).

All analyses after generation of Procrustes coordinates were performed using $\mathrm{R}$ statistical software, unless otherwise noted (R Core Team 2012).

\section{Results}

\section{Analysis of Covariance Models}

An interaction between standard length and year was not found to be a significant predictor of weight (ANCOVA, d.f $=1,26 ; F=0.10 ; P=0.760$ ) or body depth (AN- 


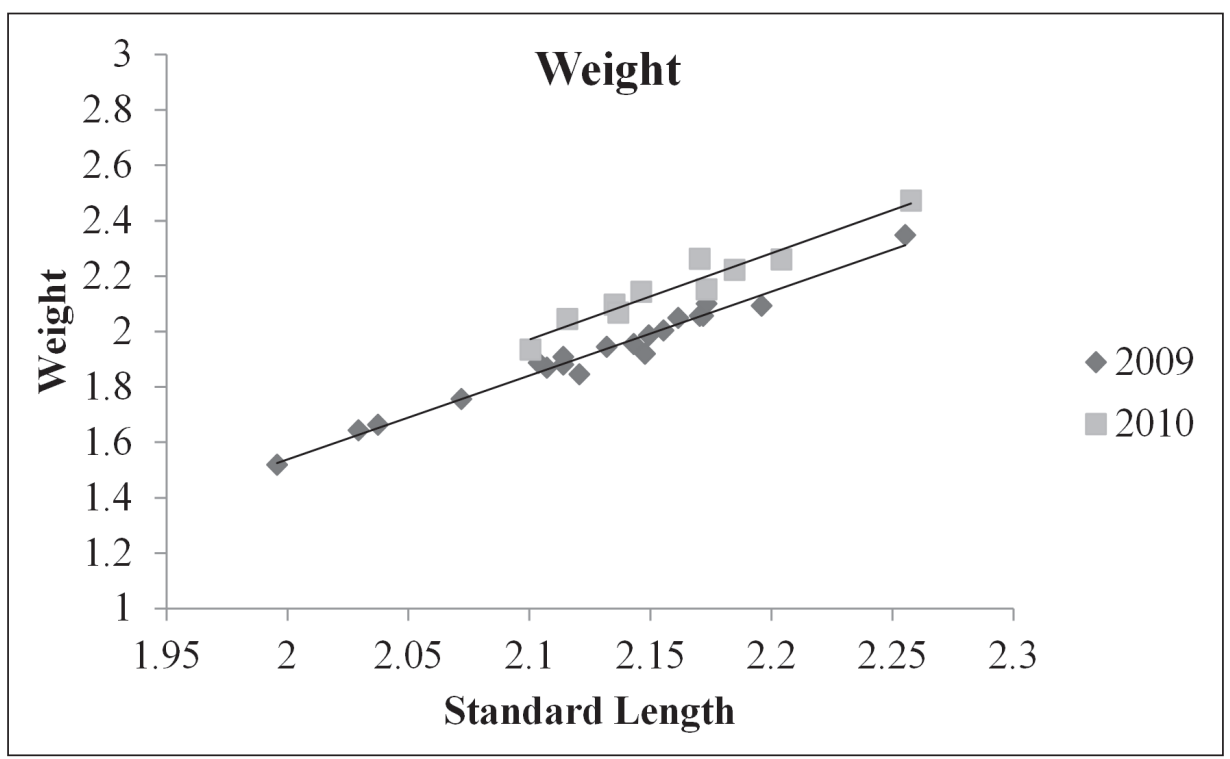

Figure 2. Relationship between log transformed standard length and log transformed weight as a scatter plot for fish from pre and post management (2009 and 2010, respectively). Two lines of best fit were created, one for each year group. The regression function for 2009 was $y=-3.03 x-4.53$, and was $y=$ $-3.12 x-4.57$ for 2010 , where $y$ is $\log _{10}$ transformed weight in grams and $x$ is $\log _{10}$ transformed standard length in $\mathrm{mm}$.

COVA, d.f. $=1,26 ; F=0.06 ; P=0.815)$, therefore it was excluded from the reduced model for both response variables. The covariate standard length was found to be significant for both the weight and the body depth ANCOVAs (ANCOVA; d.f. = 1, 27; $F=1041, P<0.001$; ANCOVA; d.f. $=1,27 ; F=539 ; P<0.001$; respectively). Weight was found to be significantly different between year groups (ANCOVA; d.f. = 1, 27; $F=109 ; P<0.001)$. Body depth was also found to be significantly different between year groups (ANCOVA; d.f. $=1,27 ; F=67 ; P<0.001$ ). The relationship between both predictor variables and standard length were plotted as a scatter plot. Lines of best fit from a linear regression were fit to fish from 2009 and 2010. These plots show that both weight and body depth were higher for fish collected post management (2010) than pre management (2009; Figs 2 and 3).

\section{Geometric Morphometrics}

The step-wise model reduction of the MANCOVA indicated there were no significant interactions included in our model (all $P$ values $>0.05$ ). Using both centroid size and standard length as covariates, year bins were significantly different with respect to Procrustes coordinates (d.f $=5,22 ; F=8.9 ; P<0.001$; Table 1 ). These data suggests that variation between years is still apparent and it aligns along the first PC axis which 


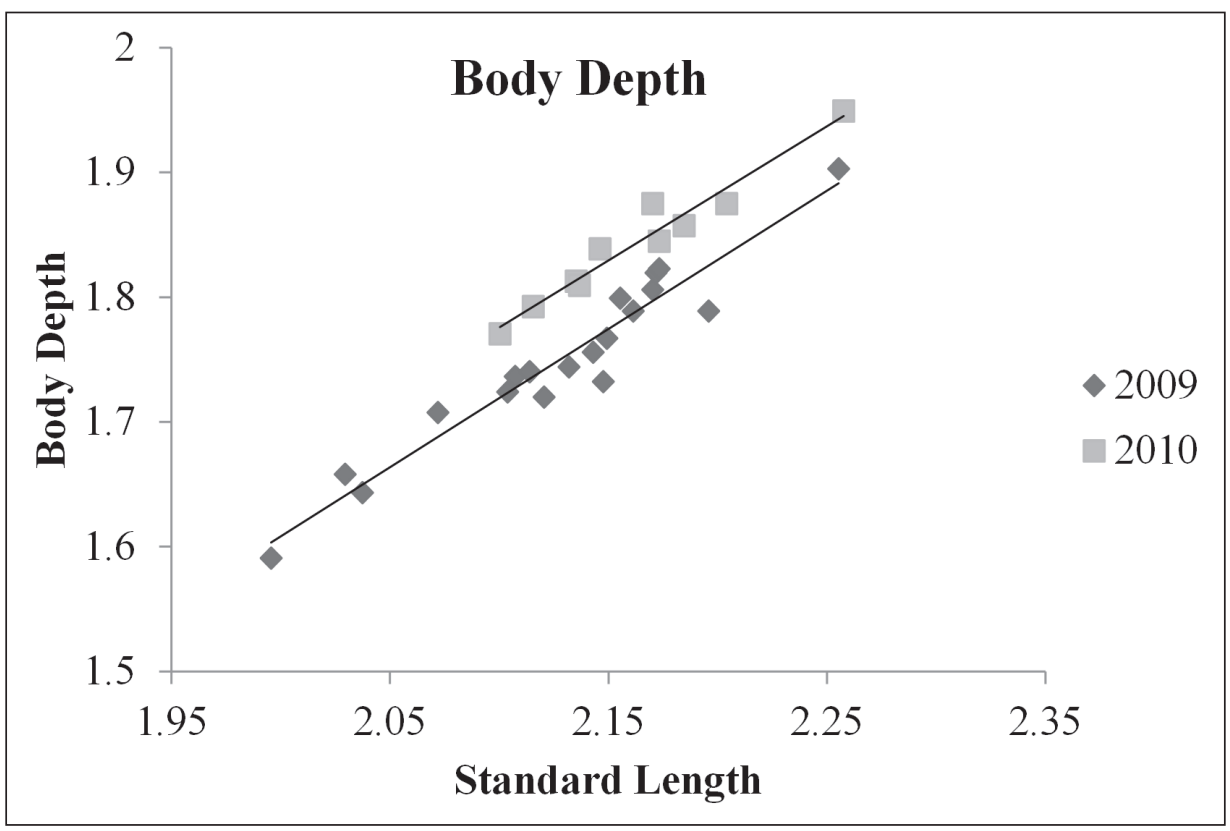

Figure 3. Relationship between log transformed standard length (x-axis) and log transformed body depth (y-axis) as a scatter plot for fish from pre and post management (2009 and 2010, respectively). Two lines of best fit were created, one for each year group. The regression function for 2009 was $y=1.11 \mathrm{x}-$ 0.61 , and was $y=1.08 x-0.48$ for 2010 , where $y$ is $\log _{10}$ transformed body depth in $\mathrm{mm}$ and $\mathrm{x}$ is $\log _{10}$ transformed standard length in $\mathrm{mm}$.

2009

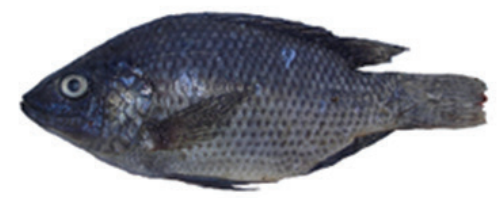

2010

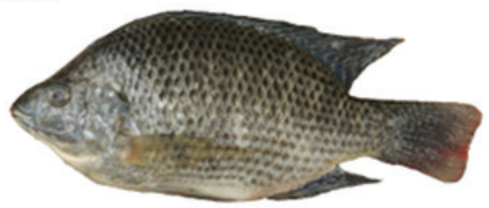

Figure 4. Representative fish from 2009 and 2010.

Table I. Table showing the results of the MANCOVA performed on shape for year bins.

\begin{tabular}{l|c|c|c|c}
\hline Effect & df & Pillai & $\boldsymbol{F}$ & $\boldsymbol{P}$ \\
\hline Standard length & 5,22 & 0.73 & 11.9 & $<0.001$ \\
\hline Centroid size & 5,22 & 0.74 & 12.8 & $<0.001$ \\
\hline Year & 5,22 & 0.67 & 8.9 & $<0.001$ \\
\hline
\end{tabular}

explains $35 \%$ of the total variation in shape among measured fish. Figure 4 shows representative fish from 2009 and 2010.

Figure 5 shows the deformation along PC1 of the bgPCA and illustrates marked differences between year categories. Procrustes coordinates near the anterior end of the 


\section{bgPCA Deformation}

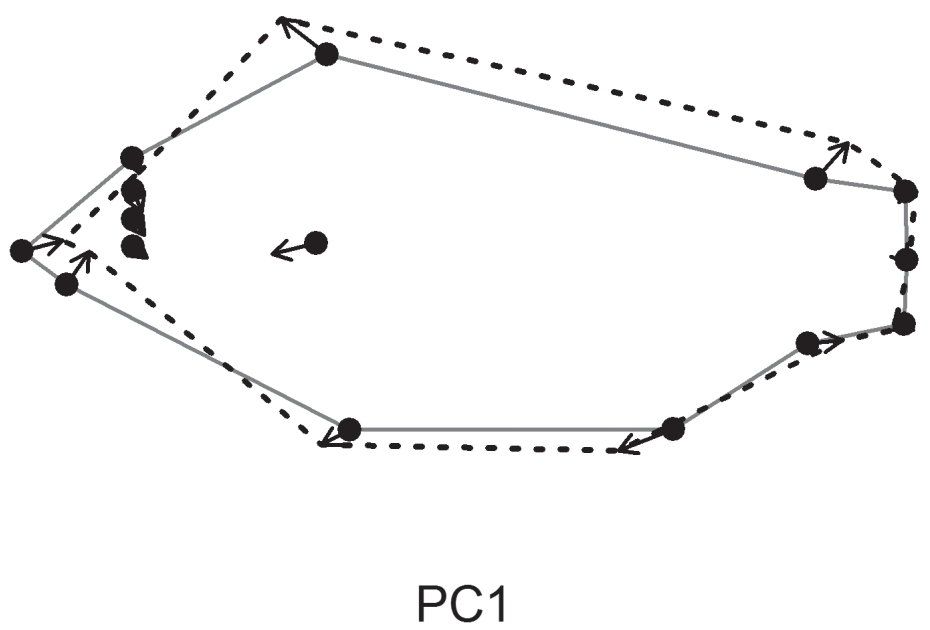

Figure 5. This figure shows the deformation along the first principal component (PC) of a between groups principal components analysis (bgPCA; between year groups). The principal components were calculated from the residuals of a multivariate regression (see Materials and Methods for more details). The solid line and points represents the mean shape of the Procrustes coordinates and the dashed line is the change along PC1 of the bgPCA. The arrows show the change for each coordinate.

fish are drawn in a posterior direction, while Procrustes coordinates at the anterior end of the dorsal and anal fins shift outward dorsoventrally and toward the anterior of the fish (Figure 5). This suggests the fish are becoming taller in body depth and shorter in overall length between year classes.

\section{Discussion}

Results from both ANCOVAs and all geometric morphometric analyses suggest that tilapia from each year bin were morphologically distinct. Post-management fish had higher bodies and were heavier per unit length than pre-management fish. The nature of our study, as well as other natural experiments, makes determining casual agents difficult if not impossible. However, the results presented here indicate that some underlying process(es) between the rotenone treatment in 2009 and 2010 caused significant changes in the morphology of tilapia from our study area.

Many possible reasons could explain this change in morphology. This apparent change in morphology could be an indicator of the success of the management plan stocking native predators. Past studies have shown that stocked predators can cause a change in the morphology of their prey (Brönmark and Miner 1992). Body depth increased in these tilapia in the same way that carp have shown increases in their body 
depth in response to predacious northern pike. It is important to consider other environmental conditions that occurred during this time, as well as other factors that are known to affect fish morphology besides predation.

After rotenone treatment there was a dramatic decrease in fish density and a clear decrease in tilapia abundance. While this is the desired effect of this method of management, it also reduces the level of competition in this habitat. Multiple tilapia could easily be caught with a blind throw of a cast net before the rotenone treatment (Lorenz pers. obs.). This sort of density can create stunting in fish, and stunting often has the opposite morphological effect of predators (Chivers et al. 2008). The higher bodied tilapia after the rotenone treatment may have acquired this morphology because of a release from such competition. Other studies on the effects of resource limitation have not been as conclusive, with different morphological changes observed in different species (Chizinski et al. 2010). The winters of 2009 and 2010 created water temperatures below 10 degrees Celsius in these canals, which is below the normally accepted lower thermal limit for this species (Green et al. 2012). The effect of temperature on morphology of fishes has been mostly unexplored, however one study did observe European sea bass (Dicentrarchus labrax) to be more slender at lower temperatures (Georgakopoulou et al. 2007). While this pattern would be opposite of our observations in this study, we felt it is important to acknowledge that temperature has been shown to affect fish morphology.

Breeding condition may also be a factor, as tilapia have been shown to have a change in body condition (and presumably morphology) depending on season (Hirpo 2012). Body condition changes were observed in Nile tilapia (Oreochromis niloticus), between the breeding and non-breeding seasons (Hirpo 2012). It is worth noting that the 2009 tilapia from this study were caught during the breeding season and the 2010 tilapia were caught out of the breeding season. It has also been shown that invasive species such as bluegill (Lepomis macrochirus) can produce different morphologies to feed on more pelagic or benthic prey (Yonekura et al. 2007). Such a large scale change in the Port Sulphur canal ecosystem driven by the rotenone treatment could have changed what food was available to the tilapia. But all stomach contents examined for both years appeared to contain only algae and detritus (Lorenz, unpublished data), leading us to believe this effect was minimal.

The relatively rapid response (possibly one generation) may indicate a stronger influence of either plasticity or a bottleneck effect as opposed to selection. There is a high probability of a founder event occurring in this closed and heavily monitored system. Founder effects are a part of invasive species biology, and this population likely had multiple founder effects (the original introduction and the dramatic decrease in individuals post-rotenone). However, a stochastic event such as the rotenone treatment was also a likely selective event on the phenotypes of the surviving fish. Morphology has been shown to change as a result of bottleneck events in fish (Shao et al. 2007), including with inbred cichlids (Winemiller and Taylor 1982). For invasive tilapia, the founder effect appeared more important than local selective forces in O. mossambicus (Firmat et al. 2012). The question of the relative importance of stochasticity, selection, and plasticity is still speculative at this point and requires further study. 


\section{Conclusion}

Invasive species are a serious threat, in part because they can be phenotypically plastic (Davidson et al. 2011) and can induce morphological changes in native species (Phillips and Shine 2006). Examining these changes can indicate the adaptability and impact of invasive species. If these changes can also indicate the success or unintended impact of management practices, there is a tremendous potential benefit. Tilapia from Port Sulphur changed significantly in morphology between pre and post-management year groups, and this change may have occurred because of the predators intentionally introduced to control their population. Further experiments could eliminate other reasons for such a change in morphology and determine if the predators were the most likely cause for the morphological changes observed. Using predatory game fish for management of invasive species can be successful, as seen with the reduction of invasive alewife (Alosa pseudoharengus) by introduced Pacific salmon (Oncorhynchus spp.) in Lake Michigan (Fenichel et al. 2010). In addition to control of non-native species, there are additional benefits gained from these methods including the preservation of biodiversity and native fisheries.

\section{Acknowledgements}

This study was possible because of a grant from the Louisiana Department of Wildlife and Fisheries acquired by the first author and M O'Connell, University of New Orleans. LDWF employees M. Kaintz and T. Ruth aided in providing specimens for examination. This manuscript represents publication No. 12 for the Nekton Research Laboratory, Pontchartrain Institute for Environmental Sciences.

\section{References}

Brönmark C, Miner JG (1992) Predator-induced phenotypical change in body morphology in crucian carp. Science 258: 1348-1350. doi: 10.1126/science.258.5086.1348

Brönmark C, Lakowitz T, Hollander J (2011) Predator-Induced Morphological Plasticity Across Local Populations of a Freshwater Snail. PLoS ONE 6(7): e21773. doi: 10.1371/ journal.pone.0021773

Chivers D, Zhao X, Brown G, Marchant T, Ferrari M (2008) Predator-induced changes in morphology of a prey fish: the effects of food level and temporal frequency of predation risk. Evolutionary Ecology 22: 561-574. doi: 10.1007/s10682-007-9182-8

Chizinski CJ, Pope KL, Wilde GR, Strauss RE (2010) Implications of stunting on morphology of freshwater fishes. Journal of Fish Biology 76: 564-579. doi: 10.1111/j.10958649.2009.02498.x

Collyer ML, Novak JM, Stockwell CA (2005) Morphological divergence of native and recently established populations of White Sands pupfish (Cypriondon tularosa). Copeia 2005: 1-11. doi: 10.1643/CG-03-303R1 
Fenichel EP, Horan RD, Bence JR (2010) Indirect Management of Invasive Species Through Bio-Controls: A Bioeconomic Model of Salmon and Alewife in Lake Michigan. Resource and Energy Economics 32: 500-518. doi: 10.1016/j.reseneeco.2010.04.002

Firmat C, Schliewen UK, Losseau M, Alibert P (2012) Body shape differentiation at global and local geographic scales in the invasive cichlid Oreochromis mossambicus. Biological Journal of the Linnean Society 105: 369-381. doi: 10.1111/j.1095-8312.2011.01802.x

Georgakopoulou E, Sfakianakis DG, Kouttouki S, Divanach P, Kentouri M, Koumoundouros G (2007) The influence of temperature during early life on phenotypic expression at later ontogenetic stages in sea bass. Journal of Fish Biology 70: 278-291. doi: 10.1111/j.10958649.2007.01305.x

Grant PR, Grant BR (2002) Unpredictable evolution in a 30-year study of Darwin's finches. Science 296: 707-711. doi: 10.1126/science.1070315

Green CC, Kelso WE, Kaller MD, Gautreaux KM, Kelly DG (2012) Potential for Naturalization of Nonidigenous Tilapia Oreochromis sp. in Coastal Louisiana Marshes Based on Integrating Thermal Tolerance and Field Data. Wetlands 32: 717-723. doi: 10.1007/s13157012-0304-x

Hirpo LA (2012) Breeding Season and Condition Factor of Oreochromis niloticus in Leke Babogaya, Ethiopia. International Journal of Agricultural Sciences 2(3): 116-120

Imre I, Mclaughlin RL, Noakes DL (2002) Phenotypic plasticity in brook char (Salvelinus fontinalis): changes in caudal fin induced by water flow. Journal of Fish Biology 61: 11711181. doi: 10.1111/j.1095-8649.2002.tb02463.x

Klingenberg C, Barluenga M, Meyer A (2003) Body shape variation in cichlid fishes of the Amphilophus citrinellus species complex. Biological Journal of the Linnean Society 80: 397-408. doi: 10.1046/j.1095-8312.2003.00246.x

Klingenberg CP (2011) MorphoJ: an integrated software package for geometric morphometrics. Molecular Ecology Resources 11: 353-357. doi: 10.1111/j.1755-0998.2010.02924.x

Langerhans RB, Layman CA, Shokrollahi AM, DeWitt TJ (2004) Predator-driven phenotypic diversification in Gambusia affinis. Evolution 58: 2305-2318.

Mitteroecker P, Bookstein F (2011) Linear Discrimination, Ordination, and the Visualization of Selection Gradients in Moddern Morphometrics. Evolutionary Biology 38: 110-114. doi: 10.1007/s11692-011-9109-8

R Core Team (2012) R: A language and environment for statistical computing. R Foundation for Statistical Computing, Vienna, Austria. ISBN 3-900051-07-0 http://www.R-project. org/

Rohlf FJ, Slice D (1990) Extensions of the Procrustes method for the optimal superimposition of landmarks. Systematic Zoology 39: 40-59. doi: 10.2307/2992207

Rohlf FJ, Marcus LF (1993) A revolution in morphometrics. Trends in Ecology and Evolution 8: 129-132. doi: 10.1016/0169-5347(93)90024-J

Rohlf FJ (2005) tpsDig, digitize landmarks and outline, version 2.05. Department of Ecology and Evolution, State University of New York at Stony Brook.

Shao Y, Wang J, Qiao Y, He Y, Cao W (2007) Morphological variability between wild populations and inbred stocks of a Chinese minnow, Gobiocypris rarus. Zoological Science 24: 1094-1102. doi: 10.2108/zsj.24.1094 
Stibor H (1992) Predator induced life-history shifts in a freshwater cladoceran. Oecologia 92: 162-165. doi: 10.1007/BF00317358

Tollrian R, Harvell CD (1999) The ecology and evolution of inducible defenses. Princeton University Press (Princeton): 1-395.

Winemiller KO, Taylor DH (1982) Inbreeding depression in the convict cichlid, Cichlasoma nigrofasciatum (Baird and Girard). Journal of Fish Biology 21: 399-402. doi: 10.1111/ j.1095-8649.1982.tb02844.x

Witte F, Welten M, Heemskerk M, van der Stap I, Ham L, Rutjes H, Wanink J (2008) Major morphological changes in a Lake Victoria cichlid fish within two decades. Biological Journal of the Linnean Society 94: 41-52. doi: 10.1111/j.1095-8312.2008.00971.x

Yonekura R, Kohmatsu Y, Yuma M (2007) Difference in the predation impact enhanced by morphological divergence between introduced fish populations. Biological Journal of the Linnean Society 91: 601-610. doi: 10.1111/j.1095-8312.2007.00821.x

Zelditch ML, Swiderski DL, Sheets HD (2012) A Practical Companion to Geometric Morphometrics for Biologists: Running Analyses in Freely-Available Software. Supplement to: Zelditch ML, Swiderski DL, Sheets HD, Fink WL (Eds) Geometric Morphometrics for Biologists: A Primer. Elservier Academic Press (New York and London): (6) 1-17. 